\title{
Heat Partition Effect on Cutting Tool Morphology in Orthogonal Metal Cutting Using Finite Element Method
}

\author{
Kamuran Kamil YEŞILKAYY*, Kemal YAMAN** \\ *The Scientific and Technical Research Council of Turkey, Defense Industries Research and Development Institute \\ (TÜBITAK-SAGE), Ankara,06261, Turkey.E-mail: kamil.yesilkaya@tubitak.gov.tr \\ **The Scientific and Technical Research Council of Turkey, Defense Industries Research and Development Institute \\ (TÜBITAK-SAGE), Ankara,06261, Turkey.E-mail: kemal.yaman@tubitak.gov.tr
}

cross $^{\text {ref }}$ http://dx.doi.org/10.5755/j01.mech.25.4.22745

\section{Introduction}

Metal cutting process is a removal of a layer of metal, which is called the chip, by a cutting tool. The heavy industries such as automotive, aerospace, construction, etc. often employ the metal cutting processes in their manufacturing activities. In the engineering field, the word "machining" is used to refer to material removal processes. These processes are classified into several groups such as turning, milling, drilling, and so on. This study uses turning operations which are widely employed in manufacturing industry. The metal cutting process consists of thermal and mechanical operations. Plastic deformation taking place within the workpiece material and frictional interactions between the cutting tool and the chip cause heat generation during the cutting process. One assumption is used at this point that nearly all the energy in the cutting process transforms into heat. The heat generated leads to an increase in tool temperature in the machining process. The elevated temperature affects the microstructure of the tool material as well as the workpiece material.

Most importantly, this results in rapid tool wear. As a result, machined part quality and tool life is severely affected. Tool life is considered as an important factor affecting the cost of the metal cutting process. Manufacturers try to avoid having many tool replacements during the cutting process. To avoid this, tool wear mechanisms have to be analysed and preventive measures have to be taken. In the machining processes, the cost of the process and the quality of the work has to be considered carefully. To be able to manage this, a way of cost reduction is investigated while maintaining the overall quality at higher levels. Therefore, temperature distribution in metal cutting processes requires to be fully identified so that the cutting process would be properly accomplished. In any metal cutting operation, the cutting instrument interacts with the workpiece material and isolates the chip from the workpiece material by breaking the bonds at the shear plane. Thus, heat is produced inside the workpiece material. It is important to find the partition and distribution of the heat sources in such orthogonal machining operations [1].

Temperatures in the orthogonal machining operations have an influence on machining performance. The microstructure of the workpiece material is modified by temperature and hence the workpiece material becomes ductile and cutting forces decrease. At the tool-chip interface, thermal interactions have a major effect on tool life due to the fact that high temperature values cause the softening of the cutting tool and thus trigger tool wear. A study in terms of temperature distribution and heat partition gives rise to the necessity of the tool coatings in such metal cutting processes.

Modelling techniques have been used to understand temperature distribution and heat partition in metal cutting operations. Main modelling techniques are analytical technique and numerical technique, i.e. Finite Element Modelling (FEM). These are often used with an experimental study to validate the results. Finite element models have gained acceptance to discover the temperature distribution characteristic in orthogonal machining operations. The reason is that the FEM gives an opportunity to find thermal parameters such as temperature, heat flux, et cetera without establishing a real cutting operation or doing a series of experiments which can be considered to causing cost and time.

Akbar et al. [2] conducted a number of experiments to find the variety of cutting forces in orthogonal machining by using uncoated and coated cutting tools. There is a decrease in cutting forces between the cutting speeds of $100 \mathrm{~m} / \mathrm{min}$ and $395 \mathrm{~m} / \mathrm{min}$, a slight increase in cutting forces between the cutting speeds of $395 \mathrm{~m} / \mathrm{min}$ and $565 \mathrm{~m} / \mathrm{min}$, and finally a fall in cutting forces in the HSM region for TiN-coated tools. Several analytical models were studied for a steady-state temperature solution in the cutting process. Two of these models are suggested by Akbar et al. are of Komanduri and Hou's [3-5] and Yong et al's models. [6]. In these models, boundary conditions are applied as heat sources in the primary and secondary deformation zones. In addition, it is assumed that most of the deformation energy during the cutting process transforms into heat. Abukhshim's [7] and Mativenga [8] presents an analysis of the contact length between the cutting tool and the chip, and tool wear for uncoated tungsten-based cemented carbide tools. A number of experiments were conducted for dry high-speed turning of EN19 alloy steel using the cutting speeds of between 200 and $1200 \mathrm{~m} / \mathrm{min}$, the feed rates of 0.14 and $0.2 \mathrm{~mm} / \mathrm{rev}$, and a constant depth of cut of $0.1 \mathrm{~mm}$. The aim of Abukhshim's study was to set up a connection between the cutting speed and the contact length in such cutting operations. Abukhshim's results showed that the contact length changes relative to the contact at the interface between the cutting tool and the chip. The cutting speed majorly affected the contact phenomena, which was different for conventional and high-speed machining conditions. It can be mentioned that the mathematical models for the calculation of contact length were quantitatively in conflict with the experimental results for high speed turning. 
A cutting process includes three regions of heat generation in the process: shearing plane zone, the interface between the tool and the chip, and the surface between the flank face of the cutting tool and the workpiece [9]. At the interface between the cutting tool and the chip, plastic deformation takes place while generating the chip by breaking the bonds between atoms along the shearing plane. After the formation of the chip, it flows along the rake face of the cutting tool. As a result, heat is generated and transferred into the cutting tool. In order to achieve the contact length value in orthogonal cutting process, various mathematical models have been developed in combination with some experimental work [10]. With the help of these models, it is possible that the process parameters of chip thickness and rake angle are qualitatively estimated and the relationship between these parameters and the contact length is then easily assumed [11]. However, quantitative differences between the results of different models are experienced. In these mathematical models, the cutting speed was not taken into consideration to address the contact length. For this reason, this study investigated the effect of the cutting speed on the contact length for the speed range of $200-1200 \mathrm{~m} / \mathrm{min}$.

Coated cutting tools are likely to improve tool performance compared to uncoated tools. Coatings can play a major role in the prevention of diffusion process at high temperatures in high speed machining. Moreover, there are different coating types. It was mentioned that physical vapor deposited (PVD) coatings are less affected by chipping in the cutting process than the chemical vapor deposited (CVD) coatings [12-13]. This makes the PVD coatings preferable for high speed cutting applications. Besides, coated cutting tools experience reduced cutting forces and improved wear resistance which improve tool life [14]. In a study by Trigger et al. [15], $12 \%$ of the heat generated was estimated to be entering the cutting tool. Stephenson et al. [16] found that $15 \%$ of the heat generated transferred into the cutting tool whereas the heat fraction value stated by Komanduri et al. [4] was $10 \%$. Blok's energy partition analysis [17] is often employed as the analytical model for thermal analyses of metal cutting operations.

Numerical approaches for metal cutting operations enable manufacturers or researchers to model the process and solve it in an economical way compared to tests in the experimental cutting process. The process can be modelled by using the geometrical and material features of the cutting tool together with the cutting parameters [1821].

In the thermal effect studies performed in the literature, both cutting tool, workpiece material and cutting medium are modelled. This real-time finite element analysis takes more and more times. Whereas in this study, only the cutting tool is modelled and a significant reduction in processing time is obtained. Therefore, the main purpose here is to generate the correct finite element model which is ready to use when deciding the tool coating thickness required for related machining operations [22]. First, we focused on the physical background of the heat transfer mechanism of orthogonal cutting.

\subsection{Heat generation}

The three deformation zones, i.e. primary, secondary, and tertiary (See Fig. 1 in Section 1.2), cause the generation of heat in machining. In terms of heat transfer into the cutting tool, the major effect comes from the secondary deformation zone. It is expected that the rake face of the cutting tool prevents heat from entering the cutting tool. Moreover, the speed of the process is another important factor in the evaluation of the heat partition analysis. Heat generation takes place in three deformation zones; primary, secondary, and tertiary. Primary deformation zone is formed due to the plastic deformation of the workpiece material. Secondary deformation zone is a result of the interaction between the tool and the chip [3]. After the formation of chip, it flows along the rake face of the tool and this generates heat in this region. Tertiary deformation zone represents rubbing between the processed workpiece surface and the tool flank face. The Power required for machining is given by;

$$
P_{c}=F_{c} \cdot V,
$$

where: $P_{c}$ is cutting power, $(\mathrm{W}) ; F_{c}$ is cutting force $(\mathrm{N})$ and $V$ is cutting velocity $(\mathrm{m} / \mathrm{s})$. If it is assumed that all cutting power transforms into heat, then total heat is given by:

$$
Q=F_{c} \cdot V
$$

Friction between the tool and the chip causes the generation of heat in the secondary deformation zone which is given by:

$$
Q_{f}=F_{\gamma} \cdot V_{c h},
$$

where: heat generated in the second. def. zone (W) is denoted by $Q_{f}$; frictional force $(\mathrm{N})$ is denoted by $F_{\gamma}$ and chip velocity $(\mathrm{m} / \mathrm{s})$ is denoted by $V_{c h}$.

$$
V_{c h}=V_{c} / \lambda_{h}
$$

where: cutting speed $(\mathrm{m} / \mathrm{s})$ is denoted by $V_{c}$ and chip compression ratio $\lambda_{h}$, given as:

$$
\lambda_{h}=t_{c h} / t
$$

here: $t_{c h}$ is actual chip thickness ( $\left.\mathrm{mm}\right)$ and $t$ is un-deformed chip thickness (mm). When Eq. (4) is substituted in Eq. (3), Eq. (6) is obtained as:

$$
\begin{aligned}
& Q_{f}=F_{\gamma} \cdot V / \lambda_{h}, \\
& F_{\gamma}=F_{c} \cdot \sin \alpha+F_{s} \cdot \cos \alpha,
\end{aligned}
$$

where: $F_{s}$ is feed force $(\mathrm{N})$ and $\alpha$ is tool rake angle.

\subsection{Heat partition}

Heat generated in the process transmits into the cutting tool, the chip, and the workpiece. This partition is shown in Fig. 1. The primary and secondary deformation zones lead to an increase of the cutting tool temperature and influence heat interaction at the interface between the cutting tool and the chip. In the primary deformation zone, local heat first transfers into the chip and then into the cut- 
ting tool due to the tool-chip interaction. As a consequence, both primary and secondary deformation zones have influence on the temperature distribution of the tool rake face $[23,24]$.

Zemzemi et al. [25] characterized the friction response between the tool and work material while dry turning of Inconel 718 with TiN coated carbide and CBN tools. An open tribometer were employed to obtain the friction and heat partition coefficients.

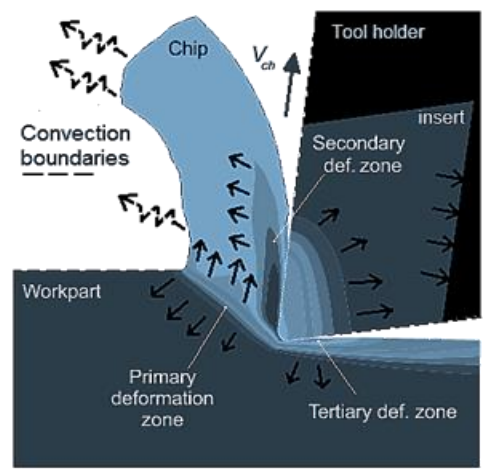

Fig. 1 Deformation zones and heat transfer mechanism

The study stated that both the friction and heat partition coefficients decrease while cutting velocity or contact pressure increases. From the study, the coefficient of heat partition $R_{t}$ is stated as shown below. While extracting the equation, the assumptions were accepted as follows; heat is generated from all existing energy during the operation and the thermal conductivity value is fixed.

$$
R_{t}=Q_{t} / F_{\gamma} \cdot V
$$

here: heat partition coefficient on tool is denoted by $R_{t}$ and heat flux on tool is denoted by $Q_{t}$. This indicates the heat flux of $R_{t} \cdot Q_{t}$ is for tool, while the one of $\left(1-R_{t}\right)$ is for workpiece. When the heat dissipation of plastic deformation of the workpiece is omitted and the existence of a relative movement between the tool and workpiece is assumed, the theoretical heat partition coefficient $R_{t-\text { theo }}$ can be calculated. A frequently employed model is specified in Eq. (9) [25].

$$
R_{t-\text { theo }}=\frac{\varepsilon_{t}}{\varepsilon_{t}+\varepsilon_{w m}}=\frac{\sqrt{k_{t} \cdot \rho_{t} \cdot c_{t}}}{\sqrt{k_{t} \cdot \rho_{t} \cdot c_{t}}+\sqrt{k_{w m} \cdot \rho_{w m} \cdot c_{w m}}},
$$

where: $\varepsilon_{w m}$ is effusivity of workpiece material, $\varepsilon_{t}$ is effusivity of tool, $k_{t}$ is tool material thermal conductivity coefficient, $k_{w m}$ is workpiece material thermal cond. coefficient, $\rho_{t}$ is tool material density, $\rho_{w m}$ is workpiece material density, $c_{t}$ is specific heat of tool and $c_{w m}$ is specific heat of workpiece.

According to the Shaw [26], the heat partition coefficient for the tool:

$$
R_{t}=1-\left\{1+\left[0.754\left(\frac{k_{t}}{k_{w m}}\right)\left(A_{a} \sqrt{N_{T}}\right)^{-1}\right]\right\}^{-1},
$$

here: $A$ is depth of cut and $l_{c}$ is contact length between tool and chip. Similarly, The Leowen-Shaw model [27] is depended on the heat zones generated in cutting operations, assuming the tool is sharp and with no chip breaking geometry. In expression (13), temperature rise between chip and tool is denoted by $\Delta \theta_{s}$ and temperature at origin point is denoted by $\theta_{0}$.

$$
R_{t}=\frac{\frac{0.377 Q l_{c}}{k_{w m} \sqrt{N_{T}}}+\Delta \theta_{s}-\theta_{0}}{\frac{Q l_{c} A_{a}}{k_{t}}+\frac{0.377 Q l_{c}}{k_{w m} \sqrt{N_{T}}}} .
$$

The model given in Eq. (13) represent the frictional heat work that formed in secondary deformation zone. On the other hand, the model includes the heat transferred from the area of sliding contact surface during the machining.

\section{Materials and method}

A Dean Smith \& Grace lathe machine was used to perform experiments in Akbar et al's study [3]. The cutting forces were quantified by a KISTLER 9121 model cutting load cell. For the experiments, tungsten-based uncoated cemented carbide and PVD TiN-coated tools (TCMW 16T304-ISO specification, triangular shape insert with 0.4 $\mathrm{mm}$ nose radius, $7^{\circ}$ clearance angle and $3.97 \mathrm{~mm}$ thickness) and Sandvik STGCR/L 2020K 16-ISO specification were used. The experimental conditions are given in Table 1. In the experiments, a pre-bored workpiece of AISI/SAE4140 alloy steel with an external diameter of $200 \mathrm{~mm}$ and $2.5 \mathrm{~mm}$ tube thickness was processed. Eight different cutting speeds, i.e. 100, 197, 314, 395, 565, 628, 785, and $880 \mathrm{~m} / \mathrm{min}$, a feed rate of $0.1 \mathrm{~mm} / \mathrm{rev}$, and a depth of cut of $2.5 \mathrm{~mm}$ were used [3]. To obtain the emissivity values, uncoated and TiN-coated inserts were heated in an oven and then their temperature values were measured by an IR thermal imaging camera (FLIR ThermaCAM-SC3000). The IR thermal imager was located near the machine turret, i.e. at a distance of $25 \mathrm{~cm}$ from the insert, and pointed on the tool rake face. The emissivity value was adjusted until the temperature reading of the thermal imager matched a thermocouple reading. The average emissivity values of 0.48 and 0.21 were found at $700^{\circ} \mathrm{C}$ for the uncoated cemented carbide and TiN-coated tool inserts re-

\begin{tabular}{|c|c|}
\hline Items & Conditions or features \\
\hline Machine tool & $\begin{array}{c}\text { Conventional lathe (Dean Smith \& } \\
\text { Grace) machine }\end{array}$ \\
\hline Workpiece & AISI/SAE 4140 \\
\hline Workpiece size & $\begin{array}{l}200 \mathrm{~mm} \text { external diameter and } \\
2.5 \mathrm{~mm} \text { tube thickness }\end{array}$ \\
\hline Cutting inserts & $\begin{array}{l}\text { TCMW16T304-5015 (UCC) and } \\
\text { TCMW 16T304 } 6620(\mathrm{TiN})\end{array}$ \\
\hline Tool holder & STGCR/L 2020K 16 \\
\hline Cutting velocity, $V c$ & $\begin{array}{c}100,197,314,395,565,628,785, \\
\text { and } 880 \mathrm{~m} / \mathrm{min}\end{array}$ \\
\hline Feed rate, $f$ & $0.1 \mathrm{~mm} / \mathrm{rev}$ \\
\hline Depth of cut, $a$ & $2.5 \mathrm{~mm}$ \\
\hline Environment & Dry orthogonal machining \\
\hline
\end{tabular}
spectively.

Table 1

Experimental conditions [3] 


\subsection{Finite element modelling}

A geometrical model which consists of a cemented carbide insert, a shim seat, and a tool holder has been generated. The CAD and FE model is shown in Fig. 2, a and Fig. 2, b respectively. The finite element mesh of the cutting tool was generated with 18580 nodes and 12027 four-node linear tetrahedron elements.

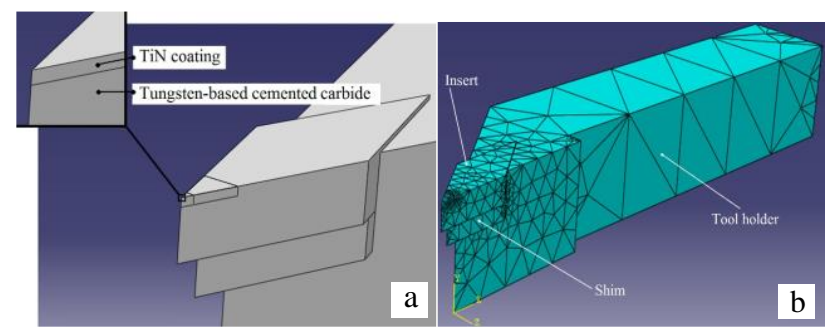

Fig. 2 (a) CAD model and (b) Meshed model for TiNcoated $(3 \mu \mathrm{m})$ cutting tool

TiN-coated cutting tools were generated in ABAQUS with the coating thickness values of 3 and 10 $\mu \mathrm{m}$ which are applicable minimum and maximum coating thicknesses for the most convenient mesh size and analysis time. The CAD model of the TiN-coated $(3 \mu \mathrm{m})$ cutting tool is shown in Fig. 2 the material properties of tool holder, shim and TiN coated tool are stated in Table 2.

Table 2

Material properties for tool holder, shim and tools (UCCTiN coated) [3]

\begin{tabular}{|c|c|c|c|c|c|c|c|}
\hline \multicolumn{2}{|c|}{ Component } & \multicolumn{2}{|c|}{ Tool holder } & \multicolumn{2}{|c|}{$\begin{array}{l}\text { Substrate } \\
\text { and shim }\end{array}$} & \multicolumn{2}{|c|}{$\begin{array}{l}\text { TiN-coated } \\
\text { tool tip }\end{array}$} \\
\hline \multicolumn{2}{|c|}{ Material } & \multicolumn{2}{|c|}{ AISI 1045} & \multicolumn{2}{|c|}{ UCC } & \multicolumn{2}{|c|}{$\mathrm{TiN}$} \\
\hline$E$ & $\begin{array}{c}\text { Young's } \\
\text { Modulus, } \\
\text { GPa }\end{array}$ & \multicolumn{2}{|c|}{207} & \multicolumn{2}{|c|}{534} & \multicolumn{2}{|c|}{250} \\
\hline$v$ & $\begin{array}{l}\text { Poisson's } \\
\text { ratio }\end{array}$ & \multicolumn{2}{|c|}{0.3} & \multicolumn{2}{|c|}{0.22} & \multicolumn{2}{|c|}{0.25} \\
\hline$\rho$ & $\begin{array}{c}\text { Density, } \\
\mathrm{kg} / \mathrm{m}^{3}\end{array}$ & \multicolumn{2}{|c|}{7844} & \multicolumn{2}{|c|}{11900} & \multicolumn{2}{|c|}{5420} \\
\hline$\kappa$ & $\begin{array}{l}\text { Thermal } \\
\text { Cond. @ } \\
\text { given } \\
\text { Temp. }{ }^{\circ} \mathrm{C} \text {, } \\
\mathrm{W} / \mathrm{m} . \mathrm{K}\end{array}$ & $\begin{array}{c}100^{\circ} \mathrm{C} \\
400^{\circ} \mathrm{C} \\
700^{\circ} \mathrm{C} \\
1000^{\circ} \mathrm{C}\end{array}$ & $\begin{array}{l}50.7 \\
41.9 \\
30.1 \\
26.8\end{array}$ & \begin{tabular}{|c|}
$100^{\circ} \mathrm{C}$ \\
$400^{\circ} \mathrm{C}$ \\
$700^{\circ} \mathrm{C}$ \\
$1000^{\circ} \mathrm{C}$
\end{tabular} & $\begin{array}{c}40.2 \\
52.8 \\
65.4 \\
78\end{array}$ & $\begin{array}{c}100 \\
400 \\
700 \\
1000\end{array}$ & $\begin{array}{c}21 \\
22.5 \\
24.3 \\
26\end{array}$ \\
\hline$C$ & $\begin{array}{c}\text { Specific } \\
\text { heat @ } \\
\text { given } \\
\text { Temp. }{ }^{\circ} \mathrm{C} \text {, } \\
\text { J/kg.K }\end{array}$ & $\begin{array}{c}100^{\circ} \mathrm{C} \\
400^{\circ} \mathrm{C} \\
700^{\circ} \mathrm{C} \\
1000^{\circ} \mathrm{C}\end{array}$ & $\begin{array}{c}470.4 \\
621.6 \\
772.8 \\
924\end{array}$ & \begin{tabular}{|c|}
$100^{\circ} \mathrm{C}$ \\
$400^{\circ} \mathrm{C}$ \\
$700^{\circ} \mathrm{C}$ \\
$1000^{\circ} \mathrm{C}$
\end{tabular} & $\begin{array}{l}346 \\
382 \\
418 \\
454\end{array}$ & $\begin{array}{c}100 \\
400 \\
700 \\
1000\end{array}$ & $\begin{array}{c}703 \\
801.2 \\
846.4 \\
859.3\end{array}$ \\
\hline
\end{tabular}

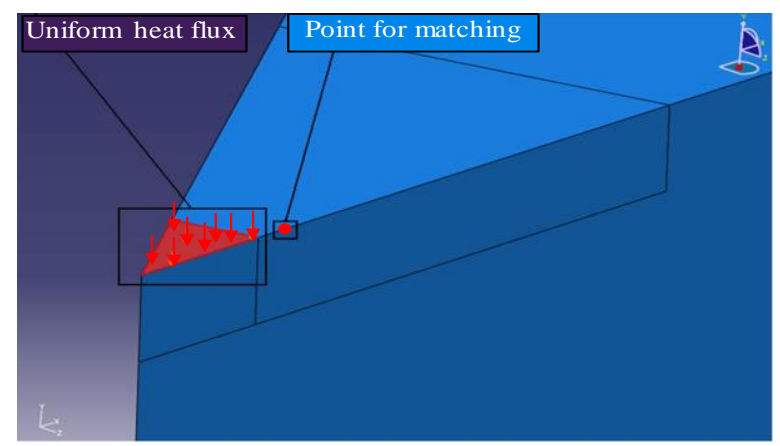

Fig. 3 Applied heat flux on the tool tip

The following boundary conditions and assumptions were used and the nomenclature of boundary conditions are given in Fig. 3:
- A plane heat source at the interface between the cutting tool and the chip was assumed.

- The initial model temperature was taken as $25^{\circ} \mathrm{C}$.

- The rear end surface of the tool holder was subjected to ambient conditions.

- The free surfaces of the insert and the holder were assigned a heat transfer coefficient $(h)$ value of 20 $\left(\mathrm{W} / \mathrm{m}^{2} \mathrm{~K}\right)$

- The thermal analysis was steady-state.

- There was no rubbing action between the workpiece and the flank face of the tool which was modelled as a rigid body.

- Tool wear was not considered in the analysis.

- The contact area between the tool and the chip was constant.

- The flank face had no effect on the fraction of heat entering the tool

- Heat generation was only associated with the rake face of the tool.

\section{Results and discussion}

Two different cutting tools have been investigated by using FEM, which were tungsten-based uncoated cemented carbide and TiN-coated tungsten-based cemented carbide inserts. Steady-state and transient temperature distributions at the tip of the cutting tool are shown in Fig. 4 and Fig. 5 for conventional machining and HSM respectively for uncoated cemented carbide (UCC) tool.

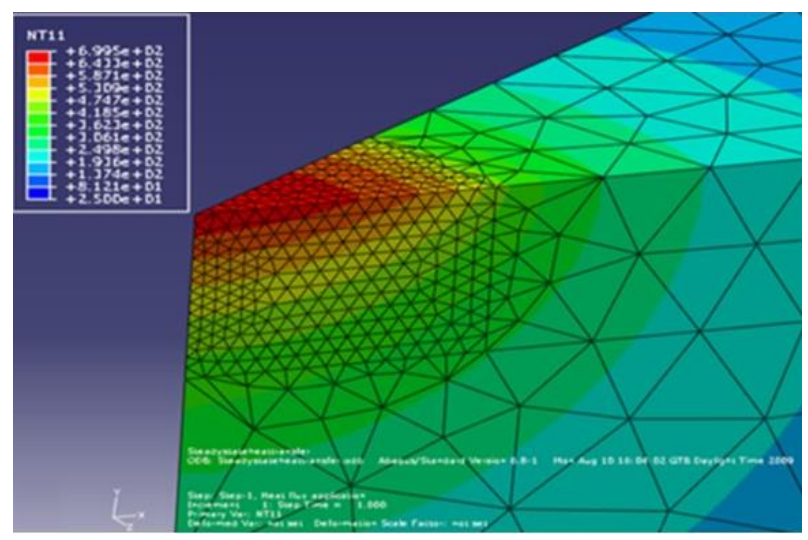

a

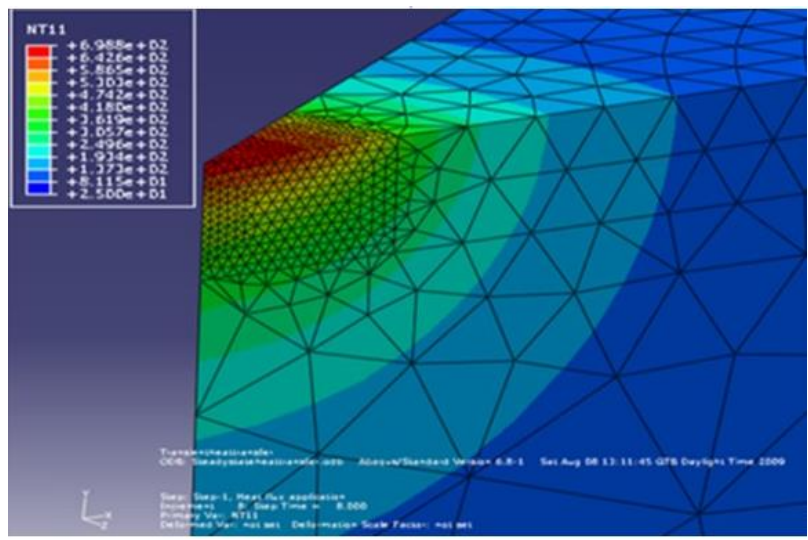

$\mathrm{b}$

Fig. 4 Temperature distribution of UCC in conventional machining (a) steady-state $(12.5 \%$ heat flux applied, $T_{\max }=699.5^{\circ} \mathrm{C}$, Area $=0.3 \mathrm{~mm}^{2}$ ) (b) transient analysis $\left(T_{\max }=698.8^{\circ} \mathrm{C}\right)$ 


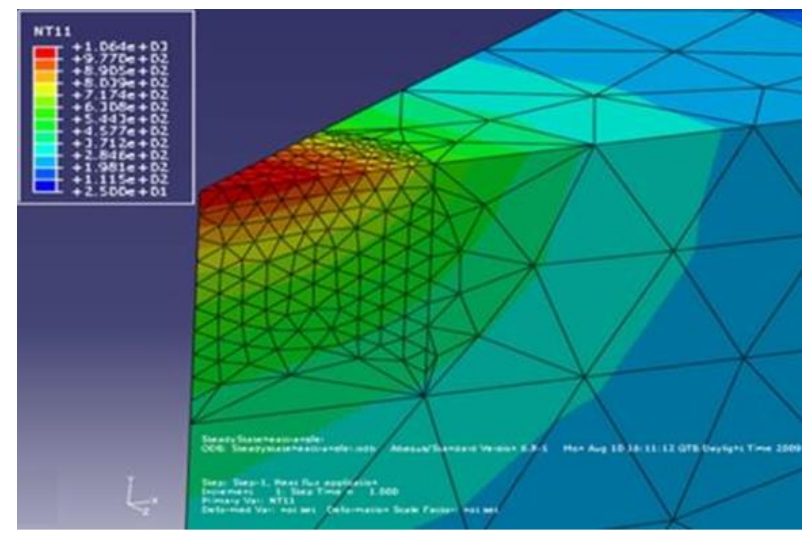

a

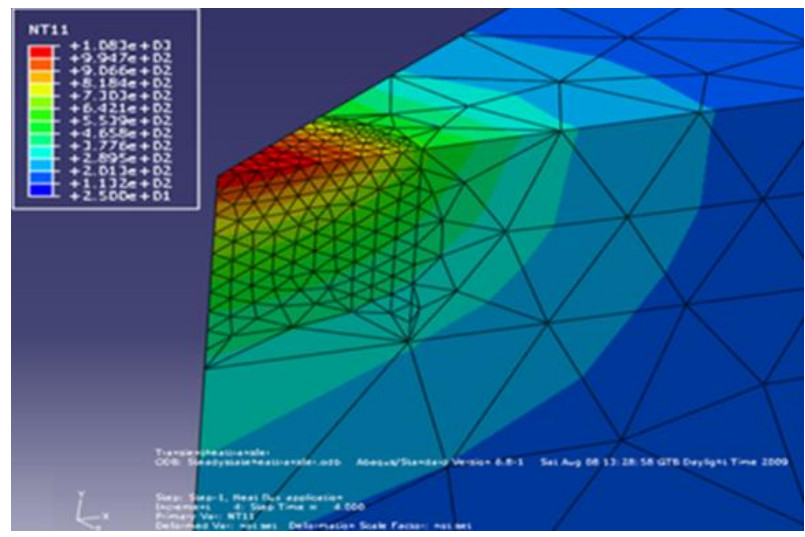

b

Fig. 5 Temperature distribution of UCC in HSM (a) steady state $\left(5.5 \%\right.$ heat flux applied, $T_{\max }=1064^{\circ} \mathrm{C}$, Area $\left.=0.1 \mathrm{~mm}^{2}\right),(\mathrm{b})$ transient analysis $\left(T_{\max }=1083\right)$

In addition, simulations for the transient heat transfer analysis for 6 seconds were completed for UCC and TiN tool in HSM respectively under constant heat flux regime $(12.5 \%)$. In the transient thermal analysis, heat transfer process takes some time to obtain temperature values of the point which were obtained from the steadystate analysis. The plots of the transient thermal analysis for the comparison of UCC and TiN tools are given in Fig. 6. The transient analysis was kept running for a period of time so that the temperature values of the steady-state analysis were reached. For HSM, the transient analysis was run for 6 seconds.

In this study, however, only thermal modelling of the cutting was taken into consideration. It was assumed that the temperatures values reach invariable values after the transient period of time. In conventional machining, the heat fraction value was $12.5 \%$ which is higher than the value in HSM. This is related to the low cutting speed which led to having more contact time and larger contact area. In high speed machining, $5.5 \%$ of the heat generated at the interface between the cutting tool and the chip, i.e. secondary deformation zone, passed into the tool due to short time of contact and heat removal mainly by the chip. On the other hand, higher temperature values were experienced in the HSM operation because of higher cutting speeds although the amount of heat flux entering the cutting tool were less than the conventional machining operation. This is connected to the fact that the smaller contact area found in high speed machining led to a limited amount of heat flowing into the cutting tool.

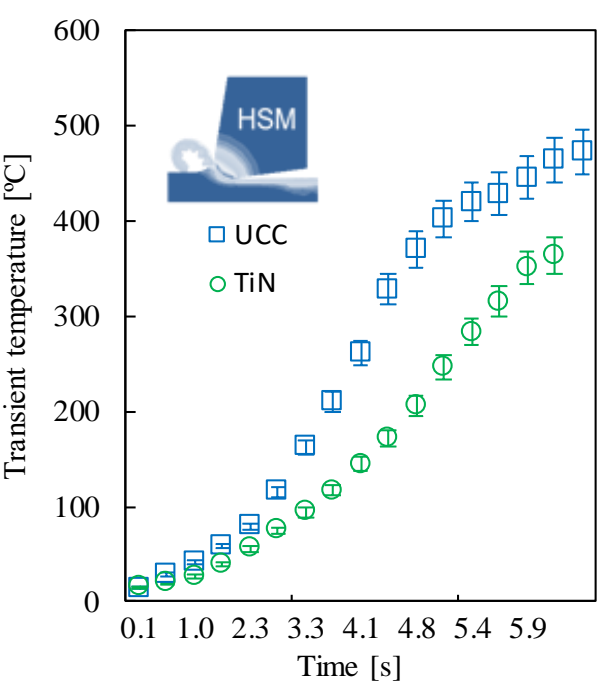

Fig. 6 UCC and TiN tool temperature comparison against time in transient thermal analysis for HSM region

Temperature values reduce when the TiN-coating film was applied on the tungsten-based uncoated cemented carbide insert. This reduction amount changes in relation to the machining mode and the coating thickness. For conventional machining, the temperature reductions of $15.6^{\circ} \mathrm{C}$ and $27.7^{\circ} \mathrm{C}$ were obtained for the coating thickness values of 3 and $10 \mu \mathrm{m}$ respectively. As it can be seen from Table 3, the temperature reduction values are higher for $\mathrm{HSM}$, which are $22^{\circ} \mathrm{C}$ and $36^{\circ} \mathrm{C}$ for the coating thickness values of 3 and $10 \mu \mathrm{m}$ respectively. The temperature reductions are achieved as a result of the decrease in the contact length and thus the contact area [3]. A higher temperature decrease in HSM occurs due to higher cutting speeds which lead to shorter time of contact, smaller contact area, and more heat removal by the chip compared to conventional machining.

Table 3

FE results for UCC and TiN-coated tool

\begin{tabular}{|c|c|c|c|c|c|}
\hline \multicolumn{2}{|c|}{ Tool conditions } & \multicolumn{2}{|c|}{$\begin{array}{l}\text { Conventional } \\
\text { machining }\end{array}$} & \multicolumn{2}{|c|}{ HSM } \\
\hline $\begin{array}{c}\text { Tool } \\
\text { Coating }\end{array}$ & $\begin{array}{c}\text { Thickness, } \\
\mu \mathrm{m}\end{array}$ & $\begin{array}{c}\text { Max. } \\
\text { Temp. } \\
T_{\max }, \\
{ }^{\circ} \mathrm{C}\end{array}$ & $\begin{array}{c}\text { Temp. } \\
\text { Reduction, } \\
{ }^{\circ} \mathrm{C}\end{array}$ & $\begin{array}{l}\text { Max. } \\
\text { Temp } \\
T_{\max }, \\
{ }^{\circ} \mathrm{C}\end{array}$ & $\begin{array}{l}\text { Temp. } \\
\text { Reduc., } \\
{ }^{\circ} \mathrm{C}\end{array}$ \\
\hline TiN & 3 & 683.2 & 15.6 & 1061 & 22 \\
\hline TiN & 10 & 671.1 & 27.7 & 1047 & 36 \\
\hline \multicolumn{2}{|c|}{ UCC } & 698.8 & - & 1083 & - \\
\hline
\end{tabular}

A higher temperature decrease in HSM takes place because of higher cutting speeds which lead to shorter time of contact, smaller contact area, and more heat removal by the chip compared to conventional machining.

The results revealed that the TiN-coated cutting tool experienced lower temperature values than the UCC cutting tool. This is related to the smaller conductivity value of the TiN-coated tool which generates a thermal barrier effect against the heat flowing into the cutting tool. The thermal conductivity of the coating film is expected to alter heat partitions for the cutting tool and the chip. It is assumed that lower thermal conductivity brings about smaller heat partition value for the cutting tool. In terms of the coated tools, higher temperature reductions were obtained from the finite element simulations for HSM in comparison to 
those for conventional machining. In HSM, the contact area between the tool and the chip is found to be smaller than the contact area in conventional machining [3]. This leads to a decrease in the amount of heat transferred into the cutting tool for HSM and hence lower temperature values for the cutting tool are experienced. In Figs. 7 and 8, Temperature distributions of TiN-coated cutting tools are given for $10 \mu \mathrm{m}$ coating thicknesses.

For higher cutting speeds, heat partition increases for uncoated cemented carbide tools while a decreasing trend continues for $\mathrm{TiN}$-coated tools due to reduction in contact area. Between the cutting speed range of 100 $395 \mathrm{~m} / \mathrm{min}$, heat partition decreases due to reduced contact area (Fig. 9). Above the cutting speed of $395 \mathrm{~m} / \mathrm{min}$, which is the high-speed region, contact area increases for uncoated cemented carbide tools (Fig. 10). The results of finite element analysis give close values in following graphs.

Contact area for TiN-coated tools decreases at higher speeds $(>395 \mathrm{~m} / \mathrm{min})$. Thus, the fraction of heat transferred into the cutting tool reduces. This shows that TiN-coated tools experience lower heat transfer compared to uncoated tools (Fig. 10). For conventional cutting speeds, the maximum difference in heat partition between experimental results and FEM results is about $15 \%$ for both tool whereas for HSM region, it is about $10 \%$ for TiN and $50 \%$ for UCC. As can be seen, TiN coatings have a more pronounced effect on decreasing the amount of heat transferred into the tool in HSM region than conventional cutting speed region.

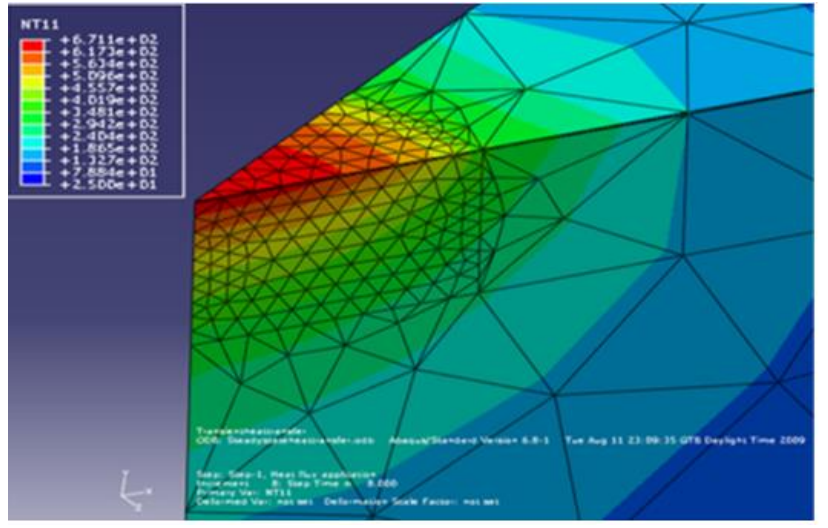

a

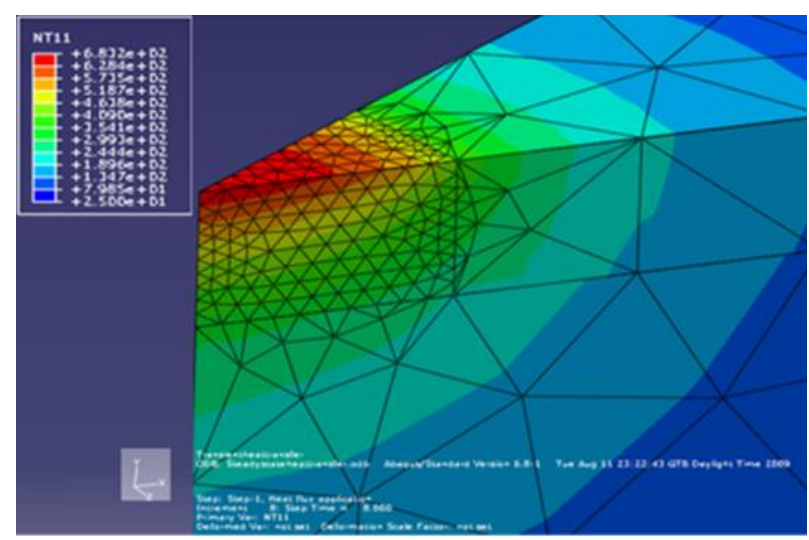

b

Fig. 7 Temperature distribution of TiN-coated cutting tool $(10 \mu \mathrm{m})$ in conventional machining (a) steady-state $\left(12.5 \%\right.$ heat flux applied, $T_{\max }=646.1^{\circ} \mathrm{C}$, Area $\left.=0.3 \mathrm{~mm}^{2}\right)$ (b) transient analysis $\left(T_{\max }=671.1^{\circ} \mathrm{C}\right)$

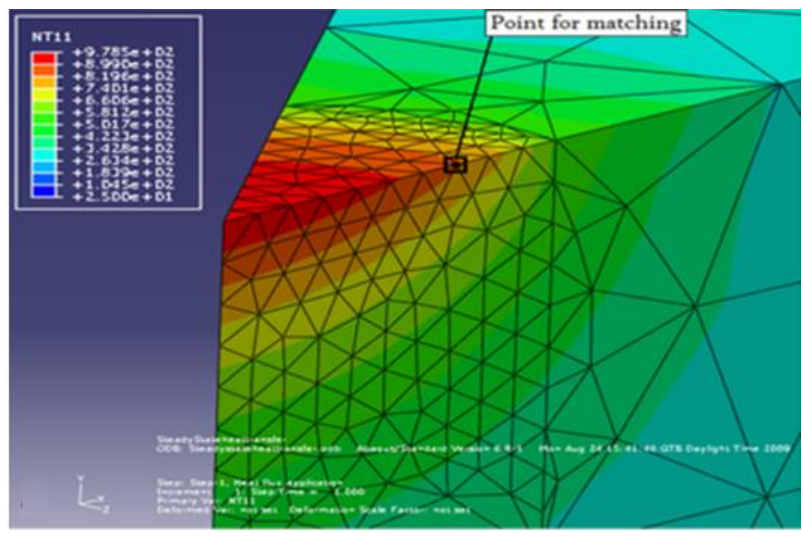

a

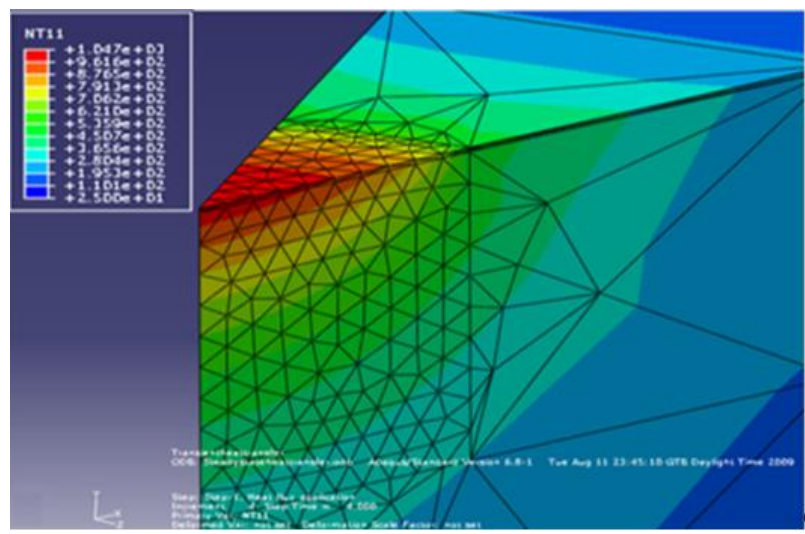

b

Fig. 8 Temperature distribution of TiN-coated cutting tool $(10 \mu \mathrm{m})$ for transient analysis in HSM (a) steadystate $\left(5.5 \%\right.$ heat flux applied, $T_{\max }=978.5^{\circ} \mathrm{C}$, Area $\left.=0.1 \mathrm{~mm}^{2}\right)$ (b) transient analysis $\left(T_{\max }=1047^{\circ} \mathrm{C}\right)$

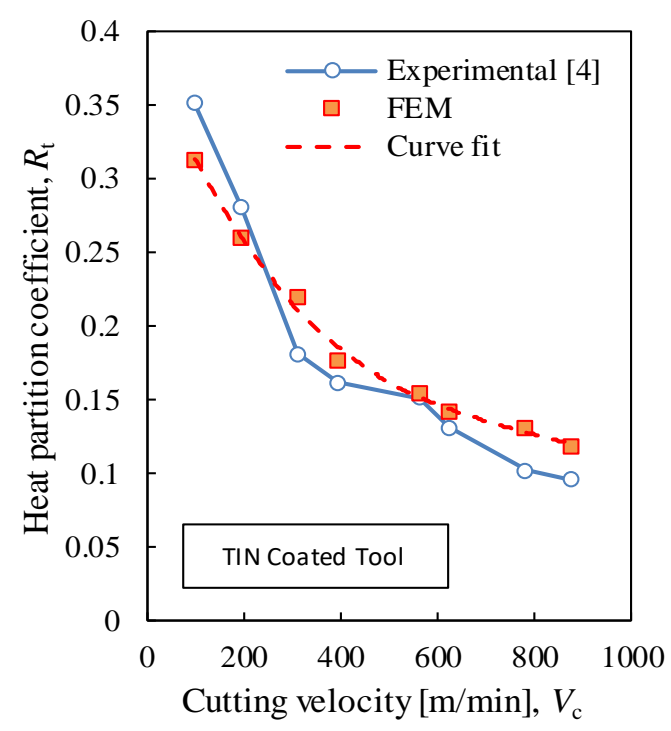

Fig. 9 Heat partition coefficient comparison against cutting velocity for TiN tool both experimentally [3] and FEM

Thermal conductivity of the tool insert defines the amount of heat flowing into the cutting tool and the chip. Low thermal conductivity leads to high chip temperature, i.e. more curled chips, and hence less amount of heat transferring into the cutting tool. As a result, the contact length between the cutting tool and the chip and hence cutting tool life are affected. Fig. 11 shows heat partition, $R_{t}$ com- 
parison against the cutting velocity for theoretical [25], Shaw [27], Leoven and Shaw [27], Experimental [3] and finite element simulation results.

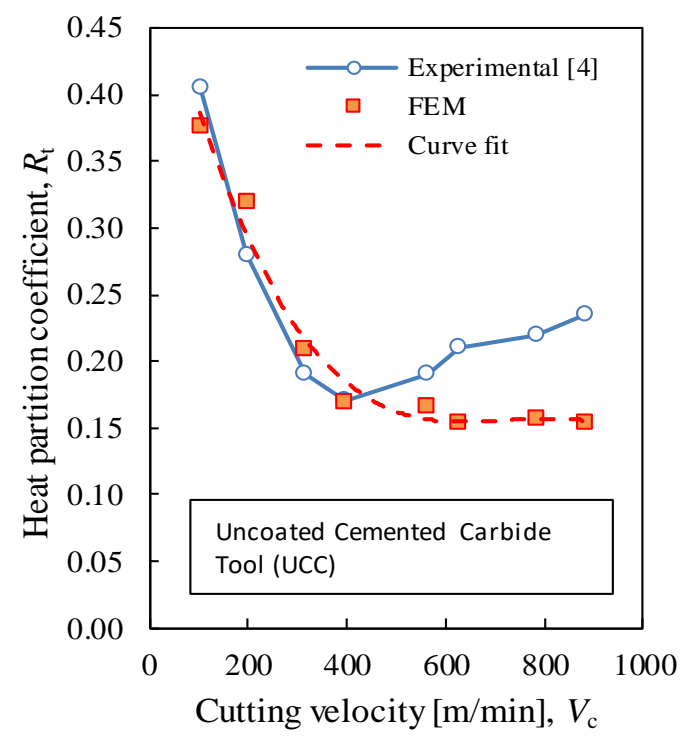

Fig. 10 Heat partition coefficient against cutting velocity for UCC tool both experimentally [3] and FEM

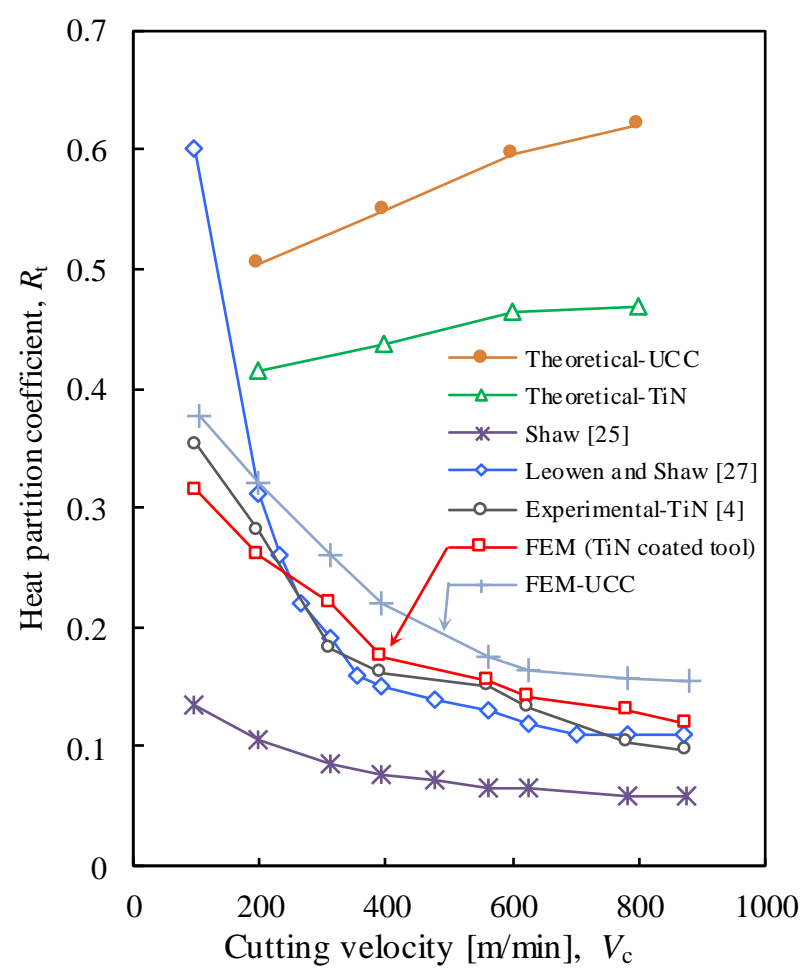

Fig. 11 Heat partition coefficient comparison against the cutting velocity for UCC, TiN-coated, Theoretical, Shaw, Leowen and Shaw, Experimental-TiN and FEM (UCC/TiN) tool

In Fig. 11, heat partition coefficients for theoretical-UCC and TiN increase with increasing the cutting speed, with maximum partition of $63 \%$ and $45 \%$ respectively. The proposed models depend on the thermal properties of the tool and the workpiece materials, and do not consider the contact process parameters. On the other hand, the Loewen-Shaw model $[27,28]$ experienced a decrease of the heat partition coefficient. It is reported that the heat partition coefficient is approximately $60 \%$ at the cutting speed of $100 \mathrm{~m} / \mathrm{min}$ while $11 \%$ at the maximum cutting speed of $880 \mathrm{~m} / \mathrm{min}$. In this case, the heat partition coefficient is modelled as a function of chip velocity, depth of cut, tool-chip contact length and most importantly, the frictional heat flux. Shaw's model [27] predicts the partition to be in between $13.6 \%$ down to $6 \%$ which represents the lowest amount of heat going into the tool among all the models.

The heat partition values of experimental TiN [3] range from $35 \%$ down to $13 \%$. The finite element model of TiN, which represents the same behavior as UCC finite element model, estimates the value in between $33 \%$ and 14\%. The TiN FEM values obtained from this study are lower than the UCC FEM values, since TiN coatings have a more pronounced effect on decreasing the amount of heat transferred into the tool. From Fig. 11, the FE models of both TiN and UCC appear to be the suitable models for predicting the heat partition values.

Both for TiN coated tools and uncoated tools, the cutting forces show a gradual decrease throughout the cutting speed range, i.e. from 100 to $800 \mathrm{~m} / \mathrm{min}$ (Fig. 12 ,a and b). Especially in Fig. 12, b, the coated tool has a more pronounced effect on cutting force reduction. In Fig. 11, heat partition coefficient decreases with increasing cutting velocity and in cutting force graphics (Figs. 12 and 13), the cutting force decreases with increasing cutting velocity. Therefore, considering these two results, it can also be asserted that the cutting force is reduced by decreasing the heat partition coefficient.
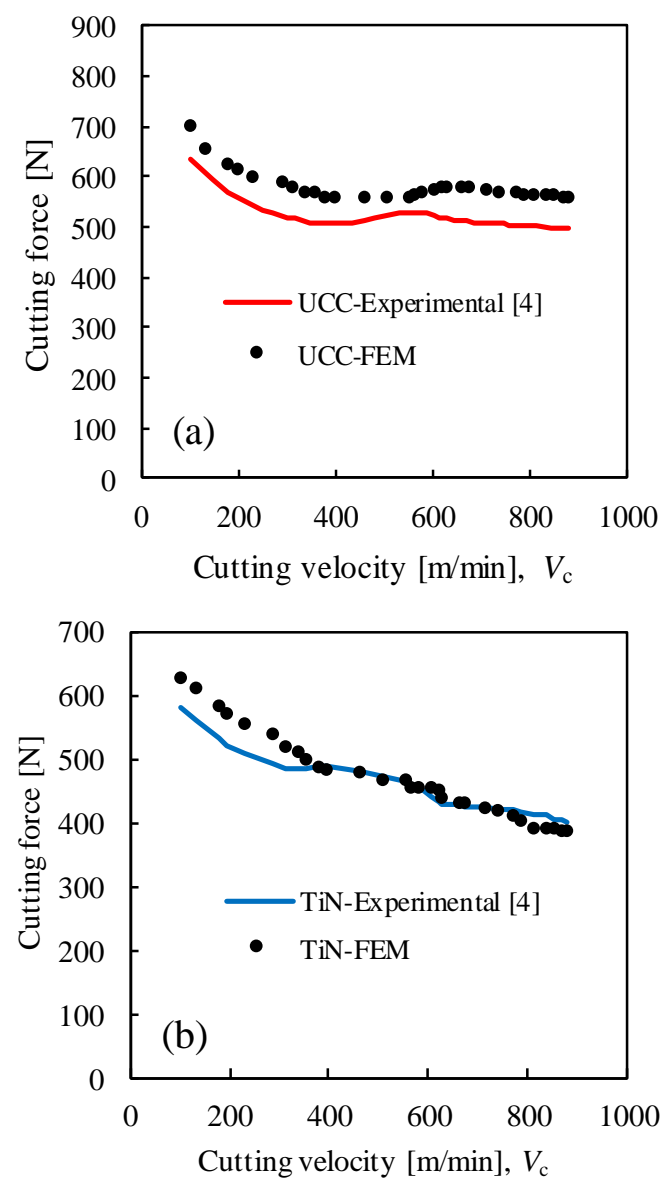

Fig. 12 (a) UCC and (b) TiN tool experimental [3] cutting force comparison against the FEM results

It can be observed that TiN coated tools experience lower cutting forces than uncoated tools (Fig. 13). 
This is due to the reduction in friction at the cutting tool interface. For this case, the good agreement is also valid for TiN and UCC tools with FE [3, 23, 29, 30].

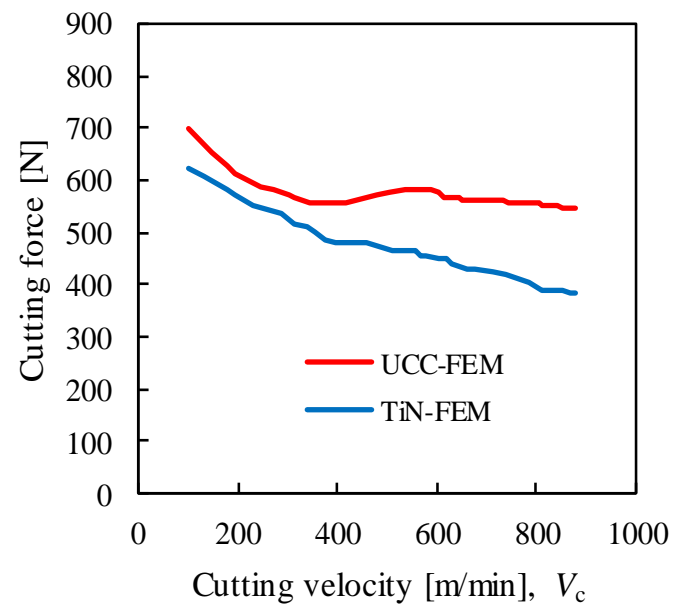

Fig. 13 UCC and TiN tool numerical cutting force comparison via the cutting velocity

\section{Conclusion}

The higher heat partition value in conventional machining was observed due to low cutting speed which leads to having more contact time and larger contact area of heat penetration. In HSM, on the other hand, relatively shorter contact duration and heat losses mainly by the chip result in lower heat partition value for the cutting tool. Tool coatings reduced the amount of heat transferred into the cutting tool. The contact area between the cutting tool and the chip decreases due to good lubrication properties of coated tools and lower thermal conductivity compared to uncoated tools. Lower temperature gradients were observed on the TiN-coated cutting tool in comparison to the UCC-uncoated cutting tool. This is attributed to the smaller conductivity value of the TiN-coated tool which generates a thermal barrier effect against the heat flowing into the cutting tool. The temperature reductions for TiN-coated tools are based on the decrease in the contact length and thus the contact area. In HSM, a higher temperature decrease was experienced due to higher cutting speeds which lead to shorter time of contact, smaller contact area, and more heat removal by the chip compared to conventional machining. Coated tools experience lower cutting forces than uncoated tools. This is due to the reduction in friction at the cutting tool interface.

\section{References}

1. Trent, E. M.; Wright, P. K. 2000. Metal cutting, 4th Edition, 1-446, Butterworth Heinemann, Newton MA, ISBN Number 0-7506-7069-X.

2. Akbar, F.; Mativenga, P. T.; Sheikh, M. A. 2008. An evaluation of heat partition in high speed turning of AISI/SAE 4140 steel with uncoated and TiN coated tools, Proceedings of the Institution of Mechanical Engineers-Part B: Journal of Engineering Manufacture 222: 759-771.

https://doi.org/10.1243/09544054JEM1072.

3. Komanduri, R.; Hou, Z. B. 2000. Thermal modelling of the metal cutting process Part 1: Temperature rise distribution due to shear plane heat source, International Journal of Mechanical Sciences 42: 1715-1752. https://doi.org/10.1016/S0020-7403(99)00070-3.

4. Komanduri, R.; Hou, Z. B. 2001. Thermal modelling of the metal cutting process Part 2: Temperature rise distribution due to frictional heat source at the tool chip interface, International Journal of Mechanical Sciences 43: 57-88. https://doi.org/10.1016/S0020-7403(99)00104-6.

5. Komanduri, R.; Hou, Z. B. 2001. Thermal modelling of the metal cutting process Part 3: Temperature rise distribution due to combined effects of shear plane heat source and the tool-chip interface frictional heat source, International Journal of Mechanical Sciences 43: 89107. https://doi.org/10.1016/S0020-7403(99)00105-8.

6. Yong, H.; Liang, S. Y. 2005. Cutting temperature modelling based on non-uniform heat intensity and partition ratio, Machining Science and Technology 9: 301323. https://doi.org/10.1080/10910340500196421.

7. Abukhshim, N. A.; Mativenga, P. T.; Sheikh, M. A. 2004. An Investigation of the tool chip contact length and wear in high speed turning of EN19 tool steel, Proceedings of the Institution of Mechanical EngineersPart B: Journal of Engineering Manufacture 218: 889903. https://doi.org/10.1243/0954405041486064.

8. Mativenga, P. T.; Abukhshim, N. A.; Sheikh, M. A.; Hon, K. K. 2006. An investigation of tool chip contact phenomena in high speed turning using coated tools, Proceedings of the Institution of Mechanical EngineersPart B: Journal of Engineering Manufacture 5: 657668. https://doi.org/10.1243/09544054JEM351.

9. Huang, L. H.; Chen, J. C.; Chang, T. 1999. Effect of tool/chip contact length on orthogonal turning performance, Journal of Industrial Technology 15: 1-5.

10. Toropov, A.; Ko, S. L. 2003. Prediction of tool-chip contact length using a new slip-line solution for orthogonal cutting, International Journal of Machine Tools and Manufacture 43: 1209-1215. https://doi.org/10.1016/S0890-6955(03)00155-X.

11. Gad, G. S.; Armarego, E. J. A.; Smith, A. J. R. 1992. Tool-chip contact length in orthogonal machining and its importance in tool temperature predictions, International Journal of Production Research 30: 485-501. https://doi.org/10.1080/00207549208942907.

12. Quinto, D. T.; Wolfe, G. J.; Jindal, P. C. 1987. High temperature micro hardness of hard coatings produced by physical and chemical vapor deposition, Thin Solid Films 153: 19-36. https://doi.org/10.1016/0040-6090(87)90166-0.

13. Quinto, D. T.; Santhanam, A. T.; Jindal, P. C. 1988. Mechanical properties, structure and performance of chemically vapor-deposited and physically vapor deposited coated carbide tools, Materials Science and Engineering A 105/106: 443-452. https://doi.org/10.1016/0025-5416(88)90729-X.

14. Edwards, R. 1993. Cutting tools, Institute of Materials, 44-49, ISBN: 9780901716484.

15. Trigger, K. J.; Chao, B. T. 1951. An analytical evaluation of metal cutting temperatures, Journal of Engi- 
neering for Industry-Transactions of the ASME 73: 5760.

16. Stephenson, D. A.; Ali, A. 1992. Tool temperatures in interrupted metal cutting, Journal of Engineering for Industry-Transactions of the ASME 14: 127-136. https://doi:10.1115/1.2899765.

17. Blok, H. 1938. Theoretical study of temperature rises at surfaces of actual contact under oiliness lubricating conditions, Proceedings of the General Discussion on Lubrication and Lubricants. The Institution of Mechanical Engineers, London, 222-235.

18. König, W.; Fritsch, R.; Kammermeier, D. 1992. New approaches to characterizing the performance of coated cutting tools, Annals of the CIRP 41: 49-54. https://doi.org/10.1016/S0007-8506(07)61150-0.

19. Rech, J.; Djouadi, M. A.; Picot, J. 2001. Wear resistance of coatings in high speed gear hobbing, Wear 250: 45-53. https://doi.org/10.1016/S0043-1648(01)00629-9.

20. Ng, E. G.; Aspinwall, D. K.; Brazil, D.; Monaghan, J. 1999. Modelling of temperature and forces when orthogonally machining hardened steel, International Journal of Machine Tools \& Manufacture 39: 885-903. https://doi.org/10.1016/S0890-6955(98)00077-7.

21. Ghani, M. U.; Abukhshim, N. A.; Sheikh, M. A. 2008. An investigation of heat partition and tool wear in hard turning of $\mathrm{H} 13$ tool steel with $\mathrm{CBN}$ cutting tools, International Journal of Advanced Manufacturing Technology 39: 874-888. https://doi.org/10.1007/s00170-007-1282-7.

22. Yesilkaya K.K. 2010. A numerical investigation of temperature distribution and heat partition in orthogonal metal cutting processes, ASME 2010 International Manufacturing Science and Engineering Conference (MSEC 2010), 12-15 October, Erie, PA, USA.

23. Fahad, M.; Mativenga, T.; Sheikh, M. A. 2013. On the contribution of primary deformation zone-generated chip temperature to heat partition in machining, International Journal of Advanced Manufacturing Technology 68: 99-110. https://doi.org/10.1007/s00170-012-4711-1.

24. Abukhshim, N. A.; Mativenga, P. T.; Sheikh, M. A. 2005. Investigation of heat partition in high speed turning of high strength alloy steel, International Journal of Machine Tools \& Manufacture 45: 1687-1695. https://doi.org/10.1016/j.ijmachtools.2005.03.008.

25. Zemzemi, F.; Rech, J.; Salem, W.B.; Dogui, A.; Kapsa, P. 2014. Identification of friction and heat partition model at the tool-chip-workpiece interfaces in dry cutting of an inconel 718 alloy with CBN and coated carbide tools, Advanced in Manufacturing Science and Technology 38: 5-22. https://doi.org/10.2478/amst-2014-0001.

26. Kagnaya, T.; Lazard, M.; Lambert, L.; Boher, C.; Cutard, T. 2011. Temperature evolution in a WC-6\% Co cutting tool during turning machining: experiment and finite element simulations, WSEAS Transactions on Heat and Mass Transfer 6: 71-80.
27. Akbar, F.; Mativenga, T.; Sheikh, M. A. 2008. An evaluation of heat partition models in high speed machining of AISI/SAE 4140 steel, The $6^{\text {th }}$ International Conference on Manufacturing Research, Brunel University, 9-1 $1^{\text {th }}$ September, U.K.

28. Ye, G.G.; Xue, S.F.; Ma, W.; Jiang, M.Q.; Ling, Z.; Tong, X.H.; Dai, L.H. 2012. Cutting AISI 1045 steel at very high speeds, International Journal of Machine Tools \& Manufacture 56: 1-9. https://doi.org/10.1016/j.ijmachtools.2011.12.009.

29. Devillez, A.; Schneider, F.; Dominiak, S.; Dudzinski, D.; Larrouquere, D. 2007. Cutting forces and wear in dry machining of Inconel 718 with coated carbide tools, Wear 262: 931-942. https://doi.org/10.1016/j.wear.2006.10.009.

30. Qian, L.; Hossan, Mohammad R. 2007. Effect on cutting force in turning hardened tool steels with cubic boron nitride inserts, Journal of Materials Processing Technology 191: 274-278. https://doi.org/10.1016/j.jmatprotec.2007.03.022.

\section{K. K. Yeşilkaya, K. Yaman}

\section{HEAT PARTITION EFFECT ON CUTTING TOOL MORPHOLOGY IN ORTHOGONAL METAL CUTTING USING FINITE ELEMENT METHOD}

S u m m a r y

It is widely accepted that heat partition and temperature distribution for metal cutting process have a significant effect on the morphological features of the cutting tool. Tool life and cutting accuracy are considerably affected by temperature distribution and heat transfer mechanisms on the tool. When a finite elements model is accurately generated, an understanding of heat partition into the cutting tool without performing experiments can be gained. This study has been completed with the use of uncoated and coated tools in order to predetermine heat partition value entering the cutting tool. In terms of coated tools, tool coating was investigated to assess its effects on heat partition. Finite Element Method was mainly used in combination with the previously generated experimental data in literature. Three-dimensional uncoated and coated models were created and made compatible with finite element modeling software to be able to perform thermal analyses of the cutting process. Finite element transient and steadystate temperature values were calculated and hence the heat intensity value for the cutting tool was determined. Finally, the effect of the cutting speed on the heat partition coefficient and the cutting force is investigated and compared with respect to the coated and the uncoated tool.

Keywords: metal cutting, thermal analysis; heat partition; finite element; tool coating.

Received February 11, 2019 Accepted August 26, 2019 